\title{
Free resources for the veterinary community
}

The International Veterinary Information Service (IVIS) is an online repository of professional information for the veterinary field. Membership is free to animal health professionals, including veterinarians, veterinary students and animal health scientists, and registration is easy. Once signed in, members have access to more than 35,000 pages worth of literature. There are currently over 150,000 members who visit the website regularly.

IVIS was founded in 1998 by academic faculty from veterinary colleges and research institutes in North America and Europe, and it went live in 2000. IVIS aims to provide high-quality information on veterinary medicine online. The IVIS homepage today shows a variety of content, including an online library, a calendar of upcoming veterinary events taking place around the world and online courses available on-demand, among other topics. On one day that Lab Animal visited, the site featured a course titled "Pain Management: Focus on Large, Exotic and Laboratory Animals" from the US-based educational group VetMedTeam. The homepage also featured a cartoon by veterinary histologist and skin disease specialist Miroslav Pavlicek, and readers are invited to enter a monthly contest for the best caption.

The left-hand side of the homepage has links to resources, including books, review and journal articles and the library. There is also a link to the bookstore, and IVIS members receive a $10 \%$ discount on most purchases. The 'My IVIS' link allows members to update their registered profile and subscribe to the IVIS newsletter, available in English, Spanish or French. Newsletters going back to August 2003 are archived, and the current newsletter lists newly added book chapters and proceedings, online courses, veterinary journals and Spanish-language documents, the cartoon caption contest and the latest upcoming meetings.

The bulk of the homepage consists of boxed sections with titles such as 'Topic of the Week,' 'Recent Additions' and 'Meet the Author'. Although most of these sections may not specifically pertain to laboratory animals, they are on topics that are often of interest to lab animal researchers or caregivers, and they cover a number of interesting species. On one of the days that Lab Animal visited IVIS, the homepage featured resources on tapirs, ruminants, small animals, sea turtles, the one-humped camel and equines. The 'TOP 40' section included links to pieces on transfusion practice, neurological examination in small animals, pain physiology and treatment, and injectable anesthesia in dogs. This homepage content changes daily. Of note, there are links provided for all specific texts and organizations mentioned in IVIS's articles-although several links in an article from 2004 led to sites and pages that no longer exist.

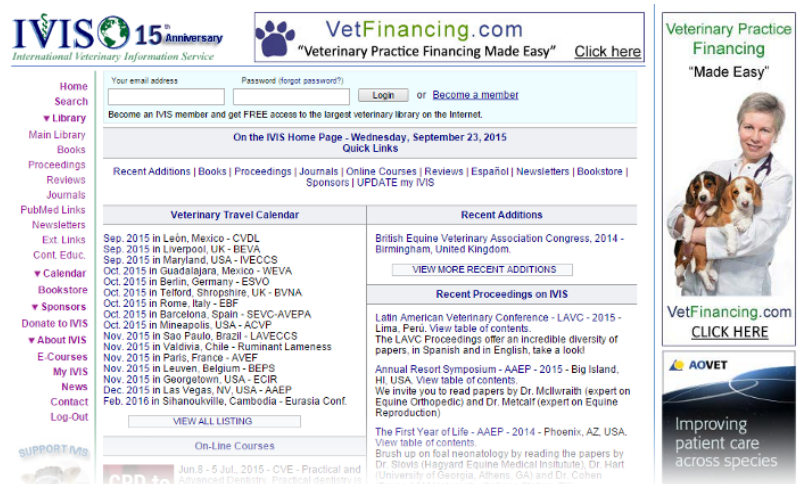

With all of this information at hand, the search function is the best way to find specific information, such as topics related to laboratory animals, according to Irma Revah, editor-in-chief of IVIS. This can be accessed either from a link on the left side of an IVIS webpage or from a box that appears at the center of the homepage once a member has logged in. A test search of all documents for the term "laboratory animals" resulted in 2,540 hits. One of them was the chapter "Environmental enrichment for laboratory animals," by K. Stewart and Kathryn Bayne, from the book Laboratory Animal Medicine and Management, edited by J.D. Reuter and M.A. Suckow. A search for the term "rat" resulted in 721 hits. One of these results was an abstract of a paper from the Proceedings of the Society for Theriogenology 2013 Annual Conference, titled "Female rat reproductive anatomy and non-surgical embryo transfer."

As IVIS obtains new documents regularly, it is a good idea to periodically check the site for new information on specific animals and areas of interest. Its lists of veterinary meetings and of veterinary online or continuing education courses are extensive, and these should certainly be checked often.

One aspect that sets this site apart is that it allows members to directly contact IVIS authors and editors, who are distinguished veterinarians and veterinary researchers from around the world. This can be done by clicking on the name of an author or editor in an article or by clicking 'Authors \& Editors' in the 'About IVIS' link on the left-hand side of the homepage. This list contained several names that are familiar to Lab Animal.

The IVIS site contains information in English, Spanish and French. It is loaded with materials that are not only useful to the laboratory animal community but often are just plain interesting.

\section{http://www.IVIS.org}
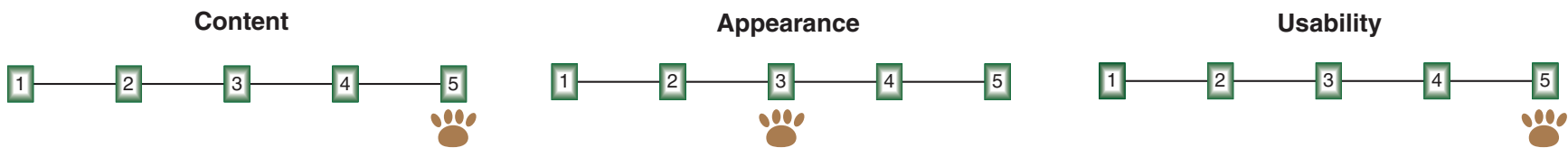